OCDE/GD(95)66

OECD SERIES ON PRINCIPLES OF GOOD LABORATORY PRACTICE AND COMPLIANCE MONITORING

Number 2 (Revised)

GUIDANCE FOR GLP MONITORING AUTHORITIES

REVISED GUIDES FOR COMPLIANCE MONITORING PROCEDURES FOR GOOD LABORATORY PRACTICE

ENVIRONMENT MONOGRAPH NO. 110

ORGANISATION FOR ECONOMIC CO-OPERATION AND DEVELOPMENT

Paris 1995

COMPLETE DOCUMENT AVAILABLE ON OLIS IN ITS ORIGINAL FORMAT 
OECD SERIES

ON

PRINCIPLES OF GOOD LABORATORY PRACTICE AND COMPLIANCE MONITORING

Number 2 (Revised)

Guidance for GLP Monitoring Authorities

\section{REVISED GUIDES FOR COMPLIANCE MONITORING PROCEDURES FOR GOOD LABORATORY PRACTICE}

ENVIRONMENT MONOGRAPH NO. 110

\section{Environment Directorate}

ORGANISATION FOR ECONOMIC CO-OPERATION AND DEVELOPMENT

Paris 1995 


\section{Copyright OECD, 1995}

Applications for permission to reproduce or translate all or part of this material should be made to: Head of Publications Service, OECD, 2 rue André-Pascal, 75775 Paris Cedex 16, France. 


\section{FOREWORD}

The 1981 Council Decision on Mutual Acceptance of Data [C(81)30(Final)], of which the OECD Principles of Good Laboratory Practice ${ }^{1}$ are an integral part, includes an instruction for OECD to undertake activities "to facilitate internationally-harmonized approaches to assuring compliance" with the GLP Principles. Consequently, in order to promote the implementation of comparable compliance monitoring procedures, and international acceptance, among Member countries the Council adopted in 1983 the Recommendation concerning the Mutual Recognition of Compliance with Good Laboratory Practice [C(83)95(Final)], which set out basic characteristics of the procedures for monitoring compliance.

A Working Group on Mutual Recognition of Compliance with GLP was established in 1985, under the chairmanship of Professor V. Silano (Italy), to facilitate the practical implementation of the Council acts on GLP, develop common approaches to the technical and administrative problems related to GLP compliance and its monitoring, and develop arrangements for the mutual recognition of compliance monitoring procedures. The following countries and organisations participated in the Working Group: Australia, Belgium, Canada, Denmark, the Federal Republic of Germany, Finland, France, Italy, Japan, Norway, the Netherlands, Portugal, Spain, Sweden, Switzerland, the United Kingdom, the United States, the Commission of the European Communities, the International Organization for Standardization, the Pharmaceuticals Inspections Convention, and the World Health Organization.

The Working Group developed, inter alia, Guides for Compliance Monitoring Procedures for Good Laboratory Practice, which concern the requisites of administration, personnel and GLP compliance monitoring programmes. These were first published in 1988 in the Final Report of the Working Group. ${ }^{2}$ A slightly abridged version was annexed to the 1989 Council Decision-Recommendation on Compliance with Principles of Good Laboratory Practice [C(89)87(Final)], which superseded and replaced the 1983 Council Act.

In adopting that Decision-Recommendation, the Council in Part III.1 instructed the Environment Committee and the Management Committee of the Special Programme on the Control of Chemicals to ensure that the "Guides for Compliance Monitoring Procedures for Good Laboratory Practice" and the "Guidance for the Conduct of Laboratory Inspections and Study Audits" set out in Annexes I and II thereto were updated and expanded, as necessary, in light of developments and experience of Member countries and relevant work in other international organisations.

1 See The OECD Principles of Good Laboratory Practice, No. 1 in this OECD series on Principles of GLP and Compliance Monitoring.

2 Final Report of the Working Group on Mutual Recognition of Compliance with Good Laboratory Practice, OECD Environment Monograph No. 15, March 1988. 
The OECD Panel on Good Laboratory Practice developed proposals for amendments to these Annexes, as well as to Annex III which provides "Guidance for the Exchange of Information concerning National Programmes for Monitoring of Compliance with the Principles of Good Laboratory Practice" and which was amended essentially to include an appendix on "Guidance for Good Laboratory Practice Monitoring Authorities for the Preparation of Annual Overviews of Test Facilites Inspected". These revised Annexes were approved by the Council in a Decision "Amending the Annexes to the Council DecisionRecommendation on Compliance with Principles of Good Laboratory Practice on 9th March, 1995 [C(95)8(Final)].

Part I of this Publication consists of the Revised Guides for Compliance Monitoring Procedures for Good Laboratory Practice, as annexed to the 1989 Council Act [C(89)87(Final)] and revised by Council in 1995 [C(95)8(Final)]. The text of that Council Act will be found in Part Two, together with revised Annex III.

This document cancels and replaces the Environment Monograph no. 46 entitled "Guides for Compliance Monitoring Procedures for Good Laboratory Practice", published in 1992. 


\section{CONTENTS}

Part One: Revised Guides for Compliance Monitoring Procedures for

Good Laboratory Practice

Part Two: Council Decision-Recommendation on Compliance with

Principles of Good Laboratory Practice ([C(89)87(Final)]

Annex III: Revised Guidance for the Exchange of Information concerning National Procedures for Monitoring Compliance 


\title{
PART ONE:
}

\section{REVISED GUIDES FOR COMPLIANCE MONITORING PROCEDURES FOR GOOD LABORATORY PRACTICE ${ }^{3}$}

\author{
(As revised by the Council, on 9th March, 1995)
}

To facilitate the mutual acceptance of test data generated for submission to Regulatory Authorities of OECD Member countries, harmonization of the procedures adopted to monitor good laboratory practice compliance, as well as comparability of their quality and rigour, are essential. The aim of this document is to provide detailed practical guidance to OECD Member countries on the structure, mechanisms and procedures they should adopt when establishing national Good Laboratory Practice compliance monitoring programmes so that these programmes may be internationally acceptable.

It is recognised that Member countries will adopt GLP Principles and establish compliance monitoring procedures according to national legal and administrative practices, and according to priorities they give to, e.g., the scope of initial and subsequent coverage concerning categories of chemicals and types of testing. Since Member countries may establish more than one Good Laboratory Practice Monitoring Authority due to their legal framework for chemicals control, more than one Good Laboratory Practice Compliance Programme may be established. The guidance set forth in the following paragraphs concerns each of these Authorities and Compliance Programmes, as appropriate.

\section{DEFINITIONS OF TERMS}

The definitions of terms in the "OECD Principles of Good Laboratory Practice" [Annex 2 to Council Decision C(81)30(Final)] are applicable to this document. In addition, the following definitions apply:

GLP Principles: Principles of good laboratory practice that are consistent with the OECD Principles of Good Laboratory Practice as set out in Annex 2 of Council Decision C(81)30(Final).

GLP Compliance Monitoring: The periodic inspection of test facilities and/or auditing of studies for the purpose of verifying adherence to GLP Principles.

(National) GLP Compliance Programme: The particular scheme established by a Member country to monitor good laboratory practice compliance by test facilities within its territories, by means of inspections and study audits.

3 The Revised Guides for Compliance Monitoring Procedures for Good Laboratory Practice are contained in the revision of Annex I to the Council Decision-Recommendation on Compliance with Principles of Good Laboratory Practice $[\mathrm{C}(89) 87$ (Final)] and $[\mathrm{C}(95) 8$ (Final)]. For the text of $\mathrm{C}(89) 87$ (Final), see page 15 of this publication.

4 See The OECD Principles of Good Laboratory Practice, No.1 in this OECD series on Principles of GLP and Compliance Monitoring. 
(National) GLP Monitoring Authority: A body established within a Member country with responsibility for monitoring the good laboratory practice compliance of test facilities within its territories and for discharging other such functions related to good laboratory practice as may be nationally determined. It is understood that more than one such body may be established in a Member country.

Test Facility Inspection: An on-site examination of the test facility's procedures and practices to assess the degree of compliance with GLP Principles. During inspections, the management structures and operational procedures of the test facility are examined, key technical personnel are interviewed, and the quality and integrity of data generated by the facility are assessed and reported.

Study Audit: A comparison of raw data and associated records with the interim or final report in order to determine whether the raw data have been accurately reported, to determine whether testing was carried out in accordance with the study plan and Standard Operating Procedures, to obtain additional information not provided in the report, and to establish whether practices were employed in the development of data that would impair their validity.

Inspector: A person who performs the test facility inspections and study audits on behalf of the (National) GLP Monitoring Authority.

GLP Compliance Status: The level of adherence of a test facility to the GLP Principles as assessed by the (National) GLP Monitoring Authority.

Regulatory Authority: A national body with legal responsibility for aspects of the control of chemicals.

\section{COMPONENTS OF GOOD LABORATORY PRACTICE COMPLIANCE MONITORING PROCEDURES}

\section{Administration}

A (National) GLP Compliance Programme should be the responsibility of a properly constituted, legally identifiable body adequately staffed and working within a defined administrative framework.

Member countries should:

- ensure that the (National) GLP Monitoring Authority is directly responsible for an adequate "team" of inspectors having the necessary technical/scientific expertise or is ultimately responsible for such a "team";

— publish documents relating to the adoption of GLP Principles within their territories;

- publish documents providing details of the (National) GLP Compliance Programme, including information on the legal or administrative framework within which the programme operates and references to published acts, normative documents (e.g., regulations, codes of practice), inspection manuals, guidance notes, periodicity of inspections and/or criteria for inspection schedules, etc.;

- maintain records of test facilities inspected (and their GLP Compliance Status) and of studies audited for both national and international purposes. 


\section{Confidentiality}

(National) GLP Monitoring Authorities will have access to commercially valuable information and, on occasion, may even need to remove commercially sensitive documents from a test facility or refer to them in detail in their reports.

Member countries should:

- make provision for the maintenance of confidentiality, not only by Inspectors but also by any other persons who gain access to confidential information as a result of GLP Compliance Monitoring activities;

- ensure that, unless all commercially sensitive and confidential information has been excised, reports of Test Facility Inspections and Study Audits are made available only to Regulatory Authorities and, where appropriate, to the test facilities inspected or concerned with Study Audits and/or to study sponsors.

\section{Personnel and Training}

(National) GLP Monitoring Authorities should:

— ensure that an adequate number of Inspectors is available

The number of Inspectors required will depend upon:

i) the number of test facilities involved in the (National) GLP Compliance Programme;

ii) the frequency with which the GLP Compliance Status of the test facilities is to be assessed;

iii) the number and complexity of the studies undertaken by those test facilities

iv) the number of special inspections or audits requested by Regulatory Authorities.

- ensure that Inspectors are adequately qualified and trained

Inspectors should have qualifications and practical experience in the range of scientific disciplines relevant to the testing of chemicals. (National) GLP Monitoring Authorities should:

i) ensure that arrangements are made for the appropriate training of GLP Inspectors, having regard to their individual qualifications and experience;

ii) encourage consultations, including joint training activities where necessary, with the staff of (National) GLP Monitoring Authorities in other Member countries in order to promote international harmonization in the interpretation and application of GLP Principles, and in the monitoring of compliance with such Principles.

- ensure that inspectorate personnel, including experts under contract, have no financial or other interests in the test facilities inspected, the studies audited or the firms sponsoring such studies 
— provide Inspectors with a suitable means of identification (e.g., an identity card).

Inspectors may be:

— on the permanent staff of the (National) GLP Monitoring Authority;

— on the permanent staff of a body separate from the (National) GLP Monitoring Authority; or

- employed on contract, or in another way, by the (National) GLP Monitoring Authority to perform Test Facility Inspections or Study Audits.

In the latter two cases, the (National) GLP Monitoring Authority should have ultimate responsibility for determining the GLP Compliance Status of test facilities and the quality/acceptability of a Study Audit, and for taking any action based on the results of Test Facility Inspections or Study Audits which may be necessary.

\section{(National) GLP Compliance Programmes}

GLP Compliance Monitoring is intended to ascertain whether test facilities have implemented GLP Principles for the conduct of studies and are capable of assuring that the resulting data are of adequate quality. As indicated above, Member countries should publish the details of their (National) GLP Compliance Programmes. Such information should, inter alia:

— define the scope and extent of the Programme

A (National) GLP Compliance Programme may cover only a limited range of chemicals, e.g., industrial chemicals, pesticides, pharmaceuticals, etc., or may include all chemicals. The scope of the monitoring for compliance should be defined, both with respect to the categories of chemicals and to the types of tests subject to it, e.g., physical, chemical, toxicological and/or ecotoxicological.

— provide an indication as to the mechanism whereby test facilities enter the Programme

The application of GLP Principles to health and environmental safety data generated for regulatory purposes may be mandatory. A mechanism should be available whereby test facilities may have their compliance with GLP Principles monitored by the appropriate (National) GLP Monitoring Authority.

— provide information on categories of Test Facility Inspections/Study Audits

A (National) GLP Compliance Programme should include:

i) provision for Test Facility Inspections. These inspections include both a general Test Facility Inspection and a Study Audit of one or more on-going or completed studies;

ii) provision for special Test Facility Inspections/Study Audits at the request of a Regulatory Authority - e.g., prompted by a query arising from the submission of data to a Regulatory Authority. 
- define the powers of Inspectors for entry into test facilities and their access to data held by test facilities (including specimens, SOP's, other documentation, etc.)

While Inspectors will not normally wish to enter test facilities against the will of the facility's management, circumstances may arise where test facility entry and access to data are essential to protect public health or the environment. The powers available to the (National) GLP Monitoring Authority in such cases should be defined.

- describe the Test Facility Inspection and Study Audit procedures for verification of GLP compliance

The documentation should indicate the procedures which will be used to examine both the organisational processes and the conditions under which studies are planned, performed, monitored and recorded. Guidance for such procedures is available in Guidance for the Conduct of Test Facility Inspections and Study Audits (No. 3 in the OECD series on Principles of GLP and Compliance Monitoring).

- describe actions that may be taken as follow-up to Test Facility Inspections and Study Audits.

\section{Follow-up to Test Facility Inspections and Study Audits}

When a Test Facility Inspection or Study Audit has been completed, the Inspector should prepare a written report of the findings.

Member countries should take action where deviations from GLP Principles are found during or after a Test Facility Inspection or Study Audit. The appropriate actions should be described in documents from the (National) GLP Monitoring Authority.

If a Test Facility Inspection or Study Audit reveals only minor deviations from GLP Principles, the facility should be required to correct such minor deviations. The Inspector may need, at an appropriate time, to return to the facility to verify that corrections have been introduced.

Where no or where only minor deviations have been found, the (National) GLP Monitoring Authority may:

- issue a statement that the test facility has been inspected and found to be operating in compliance with GLP Principles. The date of the inspections and, if appropriate, the categories of test inspected in the test facility at that time should be included. Such statements may be used to provide information to (National) GLP Monitoring Authorities in other Member countries;

and/or

- provide the Regulatory Authority which requested a Study Audit with a detailed report of the findings.

Where serious deviations are found, the action taken by (National) GLP Monitoring Authorities will depend upon the particular circumstances of each case and the legal or administrative provisions under which GLP Compliance Monitoring has been established within their countries. Actions which may be taken include, but are not limited to, the following: 
- issuance of a statement, giving details of the inadequacies or faults found which might affect the validity of studies conducted in the test facility;

— issuance of a recommendation to a Regulatory Authority that a study be rejected;

- suspension of Test Facility Inspections or Study Audits of a test facility and, for example and where administratively possible, removal of the test facility from the (National) GLP Compliance Programme or from any existing list or register of test facilities subject to GLP Test Facility Inspections;

— requiring that a statement detailing the deviations be attached to specific study reports;

- action through the courts, where warranted by circumstances and where legal/ administrative procedures so permit.

\section{Appeals Procedures}

Problems, or differences of opinion, between Inspectors and test facility management will normally be resolved during the course of a Test Facility Inspection or Study Audit. However, it may not always be possible for agreement to be reached. A procedure should exist whereby a test facility may make representations relating to the outcome of a Test Facility Inspection or Study Audit for GLP Compliance Monitoring and/or relating to the action the GLP Monitoring Authority proposes to take thereon. 


\section{PART TWO:}

\section{COUNCIL DECISION-RECOMMENDATION on Compliance with Principles of Good Laboratory Practice [C(89)87(Final)]}

(Adopted by the Council at its 717th Session on 2nd October 1989)

\section{The Council,}

Having regard to Articles 5 a) and 5 b) of the Convention on the Organisation for Economic Cooperation and Development of 14th December 1960;

Having regard to the Recommendation of the Council of 7th July 1977 Establishing Guidelines in Respect of Procedure and Requirements for Anticipating the Effects of Chemicals on Man and in the Environment [C(77)97(Final)];

Having regard to the Decision of the Council of 12th May 1981 concerning the Mutual Acceptance of Data in the Assessment of Chemicals [C(81)30(Final)] and, in particular, the Recommendation that Member countries, in the testing of chemicals, apply the OECD Principles of Good Laboratory Practice, set forth in Annex 2 of that Decision;

Having regard to the Recommendation of the Council of 26th July 1983 concerning the Mutual Recognition of Compliance with Good Laboratory Practice [C(83)95(Final)];

Having regard to the conclusions of the Third High Level Meeting of the Chemicals Group (OECD, Paris, 1988);

Considering the need to ensure that test data on chemicals provided to regulatory authorities for purposes of assessment and other uses related to the protection of human health and the environment are of high quality, valid and reliable;

Considering the need to minimise duplicative testing of chemicals, and thereby to utilise more effectively scarce test facilities and specialist manpower, and to reduce the number of animals used in testing;

Considering that recognition of procedures for monitoring compliance with good laboratory practice will facilitate mutual acceptance of data and thereby reduce duplicative testing of chemicals;

Considering that a basis for recognition of compliance monitoring procedures is an understanding of, and confidence in, the procedures in the Member country where the data are generated;

Considering that harmonized approaches to procedures for monitoring compliance with good laboratory practice would greatly facilitate the development of the necessary confidence in other countries' procedures;

On the proposal of the Joint Meeting of the Management Committee of the Special Programme on the Control of Chemicals and the Chemicals Group, endorsed by the Environment Committee; 


\section{PART I}

\section{GLP Principles and Compliance Monitoring}

1. DECIDES that Member countries in which testing of chemicals for purposes of assessment related to the protection of health and the environment is being carried out pursuant to principles of good laboratory practice that are consistent with the OECD Principles of Good Laboratory Practice as set out in Annex 2 of the Council Decision C(81)30(Final) (hereafter called "GLP Principles") shall:

i) establish national procedures for monitoring compliance with GLP Principles, based on laboratory inspections and study audits;

ii) designate an authority or authorities to discharge the functions required by the procedures for monitoring compliance; and

iii) require that the management of test facilities issue a declaration, where applicable, that a study was carried out in accordance with GLP Principles and pursuant to any other provisions established by national legislation or administrative procedures dealing with good laboratory practice.

2. RECOMMENDS that, in developing and implementing national procedures for monitoring compliance with GLP Principles, Member countries apply the "Guides for Compliance Monitoring Procedures for Good Laboratory Practice" and the "Guidance for the Conduct of Laboratory Inspections and Study Audits," set out respectively in Annexes I and II which are an integral part of this DecisionRecommendation. ${ }^{5}$

\section{PART II}

\section{$\underline{\text { Recognition of GLP Compliance among Member countries }}$}

1. DECIDES that Member countries shall recognise the assurance by another Member country that test data have been generated in accordance with GLP Principles if such other Member country complies with Part I above and Part II paragraph 2 below.

2. DECIDES that, for purposes of the recognition of the assurance in paragraph 1 above, Member countries shall:

i) designate an authority or authorities for international liaison and for discharging other functions relevant to the recognition as set out in this Part and in the Annexes to this Decision-Recommendation;

5 The revision of Annex I of the Council Act [set out in C(95)8)(Final)] is Part One (pages 9-14) of this publication. Annex II will be found in No. 3 (Revised) in this OECD series on Principles of GLP and Compliance Monitoring (Environment Monograph No. 111). 
ii) exchange with other Member countries relevant information concerning their procedures for monitoring compliance, in accordance with the guidance set out in Annex $\mathrm{III}^{6}$ which is an integral part of this Decision-Recommendation; and

iii) implement procedures whereby, where good reason exists, information concerning GLP compliance of a test facility (including information focussing on a particular study) within their jurisdiction can be sought by another Member country.

3. DECIDES that the Council Recommendation concerning the Mutual Recognition of Compliance with Good Laboratory Practice [C(83)95(Final)] shall be repealed.

\section{PART III}

\section{Future OECD Activities}

1. INSTRUCTS the Environment Committee and the Management Committee of the Special Programme on the Control of Chemicals to ensure that the "Guides for Compliance Monitoring Procedures for Good Laboratory Practice" and the "Guidance for the Conduct of Laboratory Inspections and Study Audits" set out in Annexes I and $\mathrm{II}^{7}$ are updated and expanded, as necessary, in light of developments and experience of Member countries and relevant work in other international organisations.

2. INSTRUCTS the Environment Committee and the Management Committee of the Special Programme on the Control of Chemicals to pursue a programme of work designed to facilitate the implementation of this Decision-Recommendation, and to ensure continuing exchange of information and experience on technical and administrative matters related to the application of GLP Principles and the implementation of procedures for monitoring compliance with good laboratory practice.

3. INSTRUCTS the Environment Committee and the Management Committee of the Special Programme on the Control of Chemicals to review actions taken by Member countries in pursuance of this Decision-Recommendation.

For the revision of Annex III of the Council Act [Revised Guidance for the Exchange of Information concerning National Procedures for Monitoring of Compliance with Principles of Good Laboratory Practice, set out in C(95)8(Final)], see page 21 of this publication.

$7 \quad$ See note 5 , page 16. 
Annex I to C(89)87(Final)/Revised in C(95)8(Final)

REVISED GUIDES FOR COMPLIANCE MONITORING PROCEDURES FOR GOOD LABORATORY PRACTICE

See pages $9-14$

\author{
$* * *$ \\ Annex II to $\mathrm{C}(89) 87$ (Final)/Revised in $\mathrm{C}(95) 8$ (Final) \\ REVISED GUIDANCE FOR THE CONDUCT OF LABORATORY \\ INSPECTIONS AND STUDY AUDITS
}

See OECD series on Principles of GLP and Compliance Monitoring, no. 3 (Revised)

(Environment Monograph No. 111) 


\title{
REVISED GUIDANCE FOR THE EXCHANGE OF INFORMATION CONCERNING NATIONAL PROGRAMMES FOR MONITORING OF COMPLIANCE WITH PRINCIPLES OF GOOD LABORATORY PRACTICES
}

\author{
(As revised by the Council, on 9th March, 1995)
}

Part II, paragraph 2 of the Council Act contains a Decision that Member countries exchange information related to their programmes for monitoring of compliance with GLP Principles. This Annex provides guidance concerning the types of information which should be exchanged. While information concerning all of the aspects covered in the "Guides for Compliance Monitoring Programmes procedures for Good Laboratory Practice" (Annex I) are relevant to an understanding of other Member countries' programmes for GLP Compliance Monitoring, certain types of information are of particular importance. These include:

— the GLP Principles adopted nationally;

- the scope of the national programme for monitoring compliance with GLP Principles in terms of the types of chemicals and tests covered;

— the identity, legal status, and organisational structure of the (National) GLP Monitoring Authority(ies);

— the procedures followed during Test Facility Inspections and Study Audits, and the periodicity of inspections and/or criteria for inspection schedules;

— the number and qualifications of Inspectors;

- the actions available to the (National) GLP Monitoring Authority(ies) in cases of noncompliance, including the ability to inform other Member countries, when necessary, of the results of Test Facility Inspections and Study Audits;

— the arrangements for protecting confidentiality of information;

- the procedures for initiating, conducting and reporting on Test Facility Inspections and Study Audits at the request of other Member countries;

- the procedures for obtaining information on test facilities which have been inspected by a (National) GLP Monitoring Authority of another Member country, including such facilities' compliance status; and

— the nature of test facility certifications that studies were carried out following GLP Principles.

Where serious deviations which may have affected specific studies are found, the (National) GLP Monitoring Authority should consider the need to inform relevant (National) GLP Monitoring Authorities in other Member countries of their findings. 
The names of test facilities subject to Test Facility Inspections within a (National) GLP Compliance Programme, their levels of compliance with the national GLP Principles and the date(s) the Inspections were conducted should be made available annually to (National) GLP Monitoring Authorities in other Member countries upon request (see "Guidance for GLP Monitoring Authorities for the Preparation of Annual Overviews of Test Facilities Inspected" set out in the Appendix to this Annex.)

Recognition of national programmes for monitoring compliance with GLP Principles may not be immediately forthcoming from other Member countries. Member countries should be prepared to meet genuine concerns in a co-operative way. It may be that a Member country is unable to judge the acceptability of the GLP Compliance Monitoring programmes of another solely on the basis of the exchange of written information. In such cases, Member countries may seek the assurance they require through consultation and discussion with relevant (National) GLP Monitoring Authorities. In this context, OECD provides a forum for the discussion and solving of problems relating to the international harmonization and acceptance of GLP Compliance Monitoring programmes.

To facilitate international liaison and the continuing exchange of information, the establishment of a single GLP Monitoring Authority covering all good laboratory practice activities within a Member country has obvious advantages. Where more than one Authority exists, a Member country should ensure that they operate in a consistent way, and have similar GLP Compliance Programmes. The Authority or Authorities with responsibilities for international contacts should be identified by Member countries.

Situations will arise where a national Regulatory Authority of a Member country will need to request information on the GLP Compliance Status of a test facility located in another Member country. On rare occasions, and where good reason exists, a particular Study Audit may be requested by a Regulatory Authority of another Member country. Arrangements should be provided whereby these requests may be fulfilled and the results reported back to the requesting Regulatory Authority.

Formal international contact should be established for the exchange of information between GLP Monitoring Authorities. However, this should not be understood to prevent informal contacts between Regulatory Authorities and the GLP Monitoring Authority in another Member country, to the extent that such contacts are accepted by the Member countries concerned.

National authorities should note that authorities from another Member country may wish to be present at a Test Facility Inspection or Study Audit that they have specifically requested; or they may wish that representative(s) from the Member country seeking a special Test Facility Inspection or Study Audit be present at that Inspection or Audit. In these cases, Member countries should enable Inspectors from another Member country to participate in facility inspections and Study Audits carried out by their GLP Monitoring Authority. 


\section{Appendix to Annex III to C(89)87(Final)/Revised in C(95)8(Final)}

\section{GUIDANCE FOR GOOD LABORATORY PRACTICE MONITORING AUTHORITIES FOR THE PREPARATION OF ANNUAL OVERVIEWS OF TEST FACILITIES INSPECTED}

Overviews of GLP inspections should be circulated to Members of the OECD Panel on GLP and the OECD Secretariat annually before the end of March. The following minimum set of information should allow harmonisation of the overviews exchanged among national GLP monitoring authorities:

1. Identification of the facility inspected: Sufficient information should be included to make the identification of the facility unequivocal, i.e. the name of the test facility the city and country in which it is located, including inspections abroad.

2. Dates of inspections and decisions: month and year of inspection, and, if appropriate, date of final decision on GLP compliance status.

3. Nature of inspection: A clear indication should be given of whether a full GLP inspection or only a study audit was carried out, as well as whether the inspection was routine or not and any other authorities which were involved.

4. Areas of expertise of the facility inspected: Since GLP compliance is related to the tests performed by a facility, the area(s) of expertise of the test facilities inspected should be included in the annual overviews, using the following broad categories:

1) physical-chemical testing

2) toxicity studies

3) mutagenicity studies

4) environmental toxicity studies on aquatic and terrestrial organisms

5) studies on behaviour in water, soil and air; bioaccumulation

6) residue studies

7) studies on effects on mesocosms and natural ecosystems

8) analytical and clinical chemistry testing

9) other studies, specify

It is emphasised that these categories are to be used in a flexible manner on a case-by-case basis and that the aim is to provide information related to GLP compliance of test facilities that will be useful for other national monitoring authorities.

5. Compliance status: The three following categories should be used to report the compliance status of facilities:

- in compliance

- not in compliance

- pending (with explanation)

In light of the fact that "pending" is interpreted differently by Member countries and that the varying legal and administrative systems do not allow for harmonised use of the term, explanations must accompany the use of the "pending " status in the national overview of test facilities inspected. Such 
explanations could include, e.g., "pending reinspection", "pending responses from test facility". "pending completion of administrative procedures". etc.

6. Comments: If appropriate, further comments can be made.

7. Major deficiencies: At a minimum, individual studies for which a study audit has revealed serious GLP deficiencies and which have consequently been rejected by receiving authorities should be reported in the annual overviews of test facilities inspected. Since many studies are submitted to authorities in several countries at the same time, however, it is recommended that this kind of information be circulated among national authorities as rapidly as possible on an ad hoc basis, when necessary in addition to the annual overviews.

8. Statements of compliance: When statements of compliance are provided to facilities by national monitoring authorities. they should use the same terminology and categories as the annual overviews

9. Circulation of annual overviews: Overviews should be circulated annually before the end of March to the Members of the GLP Panel and the OECD Secretariat. This information can be released to the public on request. 